\title{
Inflammation-Mediated Abrogation of Androgen Signaling: An In Vitro Model of Prostate Cell Inflammation
}

\author{
Bilge Debelec-Butuner, ${ }^{1}$ Cansu Alapinar, ${ }^{2}$ Lokman Varisli, $^{2}$ Burcu Erbaykent-Tepedelen, ${ }^{2}$ \\ Syed Muhammad Hamid, ${ }^{2}$ Ceren Gonen-Korkmaz, ${ }^{3}$ and Kemal Sami Korkmaz ${ }^{2 *}$ \\ ${ }^{1}$ Department of Pharmaceutical Biotechnology, Ege University, Bornova, Izmir, Turkey \\ ${ }^{2}$ Department of Bioengineering, Cancer Biology Laboratory, Ege University, Bornova, Izmir, Turkey \\ ${ }^{3}$ Department of Pharmacology, Ege University, Bornova, Izmir, Turkey
}

\begin{abstract}
As a link between inflammation and cancer has been reported in many studies, we established an in vitro model of prostatic inflammation to investigate the loss of androgen receptor (AR)-mediated signaling in androgen responsive prostate cell lines. First, the U937 monocyte cell line was differentiated into macrophages using phorbol acetate (PMA), and cells were induced with lipopolysaccharide (LPS) for cytokine secretion. Next, the cytokine levels (TNF $\alpha$, IL6 , and IL1 $\beta$ ) in conditioned media (CM) were analyzed. Prostate cells were then fed with CM containing varying concentrations of $\mathrm{TNF} \alpha$, and IkB degradation, nuclear factor kappa B (NFkB) translocation and transactivation, and the expression of matrix metalloproteinase-8 (MMP8) and matrix metalloproteinase-9 (MMP9) were then assessed. As a result of CM treatment, ubiquitin-mediated AR degradation, which was restored using anti-TNF $\alpha$ antibody neutralization, led to both a decrease in KLK4, PSA, and NKX3.1 expression levels and the upregulation of GPX2. In addition to the loss of AR, acute and chronic CM exposure resulted in p53 degradation and consequent p21 downregulation, which was also restored by either androgen administration or ectopic NKX3.1 expression via the stabilization of MDM2 levels in LNCaP cells. Additionally, CM treatment enhanced H2AX ${ }^{(\mathrm{S} 139)}$ phosphorylation (a hallmark of DNA damage) and genetic heterogeneity in the absence of androgens in prostate cells without activating mitochondrial apoptosis. Thus, the data suggest that inflammatory cytokine exposure results in the loss of AR and p53 signaling in prostate cells and facilitates genetic heterogeneity via ROS accumulation to promote prostate carcinogenesis.
\end{abstract}

() 2012 Wiley Periodicals, Inc

Key words: prostate; NFkB; loss of p53; DNA damage; inflammation; androgen; ROS

\section{INTRODUCTION}

The secretion of inflammatory cytokines and the expression of nuclear factor kappa B (NFkB) and signal transducers and activators of transcription 3 (STAT3) have been shown to contribute to inflammation-induced cancers by mediating the ROSassociated effects within cells [1]. Many cytokines and growth factors generate reactive oxygen species (ROS) via the activation of locally recruited NADPH oxidases [2]. ROS plays a substantial role in multiple signal transduction pathways, including the TNF $\alpha$ pathway [3], and is generated in excess amounts during chronic inflammation. It is recognized that elevated ROS levels that are sustained for extended periods of time may induce DNA damage $[4,5]$. This DNA damage includes point mutations in cancerassociated genes and may result in the genetic alteration of essential cellular proteins involved in DNA repair, apoptosis, and cell cycle regulatory mechanisms [6]. Therefore, the appropriate cellular response to ROS production represents a critical event. Preventing cells from further oxidative damage is required to maintain cell survival by eliminating the damaged cells and might be advantages for multicellular organism. Although, NFкB sometimes contributes to cell death, ROS modulates the $\mathrm{NF}_{\kappa} \mathrm{B}$ response and results in the activation of $\mathrm{NF}_{\kappa} \mathrm{B}-$ mediated transcription that upregulates certain target genes that ease the expression of additional ROS production to promote cell survival [7]. Nevertheless, in prostate tissue, age-dependent factors such

\footnotetext{
Additional supporting information may be found in the online version of this article.

Lokman Varisli present address is Faculty of Science, Department of Biology, Osmanbey Campus, Harran University, Sanliurfa, Turkey.

Syed Muhammad Hamid present address is Faculty of Science, Department of Molecular Biology, Izmir Institute of Technology, Gulbahce, Izmir, Turkey.

*Correspondence to: Cancer Biology Laboratory, Department of Bioengineering, Ege University, Bornova, Izmir, Turkey.

Received 12 May 2012; Revised 5 July 2012; Accepted 24 July 2012

DOI 10.1002/mc.21948

Published online 21 August 2012 in Wiley Online Library (wileyonlinelibrary.com).
} 
as diminished AR and p53 activity may function mutually with the aforementioned mediators, and therefore, inflammation-mediated carcinogenesis may negatively influence prostate cell maintenance $[8,9]$. For this reason, molecular effects, such as functional AR transactivation and growth control, require detailed examination under inflammatory conditions.

In the presence of androgens, AR-mediated transcription regulates the expression of prostate maintenance factors and oxidative stress regulators, such as antioxidant enzymes and ROS scavengers [10]. It is well recognized that the loss of AR activity contributes to cell survival in two ways. First, the loss of AR activity results in elevated kinase activity and the expression of calcium/calmodulin-dependent kinase II (CaMKII), which leads to the growth of androgen-independent prostate cells via the activation of the anti-apoptotic PI3K/Akt pathway [11]. Second, apoptosis is weakly triggered by p53 in the absence of the AR in prostate cells even when they are exposed to genotoxic agents, such as doxorubicin and camptothecin [12]. Ouyang et al. [13] have described one putative mechanism for the cancer initiating phenotype in the prostate in which genes such as glutathione peroxidase 2 ( $G p \times 2)$, glutathione peroxidase $3(G p x 3)$, peroxiredoxin $6(\operatorname{Prd} 66)$, and sulfhydryl oxidase Q6 (Qscn6) were found to be deregulated in NKX3.1 tumor suppressor mutant mice in comparison with wild type mice. These results suggest that the AR target gene, NKX3.1, suppresses cancer initiation by protecting the cell against oxidative damage by regulating the transcription of both pro- and antioxidant enzyme encoding genes. Therefore, the loss of NKX3.1 due to proteasomal degradation induced by inflammatory cytokines such as TNF $\alpha$ and IL-1 $\beta$ [14] might be strongly linked with inflammation induced tumorigenesis, and implies that this might provide an irreversible growth advantage at the first steps of prostate carcinogenesis [14].

NKX3.1 is an androgen responsive gene and it is upregulated in the presence of androgens expressed at levels 8- to 10-fold greater than basal levels [1517]. We hypothesize that a decrease in the expression of AR target genes such as KLK4, PSA, and NKX3.1 might be reduced in association with inflammation, which may cause the prolonged activation of redox-sensitive transcription factors, such as NFкB. Thus, these events may initiate an inflammatory cascade, in which it requires the mediation of sustained oxidative damage by related mechanisms, such as the regulation of NKX3.1 expression, within the prostate cells.

Overall, our study aims to establish an in vitro prostatic inflammation model using prostate cells to study the molecular alterations associated with the inflammatory microenvironment, such as the generation of reactive oxygen species, NFкB activation, uncontrolled proliferation and the increased genetic heterogeneity due to p53 loss, and both the androgen receptor (AR)- and abrogated AR-mediated expression of NKX3.1. Therefore, we investigated the inflammatory microenvironment associated with tumorigenic alterations using LNCaP (tumor derived) and RWPE-1 (immortalized epithelial) prostate cells for acute (500 pg/ml TNF $\alpha$, up to $24 \mathrm{~h}$ ) and chronic (62 pg/ml and $125 \mathrm{pg} / \mathrm{ml} \mathrm{TNF} \alpha$, for $4 \mathrm{wk}$ ) CM treatments and analyzed the transcription levels of proliferation- and apoptosis-associated genes during inflammation using PCR arrays.

\section{MATERIALS AND METHODS}

Macrophage Differentiation and Conditioned Media (CM) Collection

The U937 monocyte cell line was cultured in RPMI 1640 medium with 10\% FBS (fetal bovine serum) at $37^{\circ} \mathrm{C}$ with $5 \% \mathrm{CO}_{2}$. To achieve macrophage differentiation and cytokine production, cells $\left(8 \times 10^{6}\right)$ were grown in $75 \mathrm{~cm}^{2}$ culture flasks for $2 \mathrm{~h}$ prior to treatment. Next, PMA was added at a final concentration of $2,4,8$, and $16 \mathrm{nM}$ for $16 \mathrm{~h}$, and adherent clusters were followed. Cells were washed twice, and $20 \mathrm{ml}$ of fresh medium was then added. After allowing the cells to rest for $2-3 \mathrm{~h}$, lipopolysaccharide (LPS) was added $(10 \mathrm{ng} / \mathrm{ml})$, and the cells were incubated for $24 \mathrm{~h}$. Finally, the supernatant (conditioned medium-CM) was collected and filtered $(0.2 \mu \mathrm{m})$ for further use.

Measurement of Cytokines in CM

Before feeding the LNCaP cells with CM, TNF $\alpha$ (Invitrogen, Carlsbad, CA), interleukin-6 (IL-6) and interleukin-1beta (IL-1 $\beta$; Boster Biological Technology Co., Fremont, CA) levels were assessed using an ELISA assay according to the manufacturer's recommendations. As the exposure is a major component in our inflammation model, the time $(0,2,4,6,12$, and $24 \mathrm{~h})$ and dose $(62.5,125,250$, and $500 \mathrm{pg} / \mathrm{ml}$ $\mathrm{TNF} \alpha$ containing $\mathrm{CM}$ ) courses of the $\mathrm{CM}$ treatment were optimized. Finally, the TNF $\alpha$ concentration was selected as a measure of the CM treatment and is given as a normalized TNF $\alpha$ concentration in the Results Section.

\section{Cell Culture and Treatments}

The LNCaP and RWPE- 1 cells were obtained from American Type Culture Collection (ATCC Manassas, VA). LNCaP cells were propagated using RPMI 1640 supplemented with 10\% FBS, L-glutamine (2 mM), penicillin $(100 \mathrm{U} / \mathrm{ml})$, and streptomycin $(100 \mu \mathrm{g} /$ $\mathrm{ml}$ ), while RWPE-1 cells were propagated in Keratinocyte growth medium supplemented with Bovine pituitary extract and $5 \mu \mathrm{M}$ EGF at $37^{\circ} \mathrm{C}$ with $5 \%$ $\mathrm{CO}_{2}$. N-acetyl-L-cysteine (L-NAC; $10 \mathrm{mM}$ ), wortmannin $(200 \mathrm{nM})$, and TBCA (200 $\mathrm{nM})$ treatments were performed for $1 \mathrm{~h}$ prior to cell incubation both with 
and without CM (500 pg/ml TNF $\alpha)$ for 6 and $24 \mathrm{~h}$. For chronic inflammation, cells were fed with 62 and $125 \mathrm{pg} / \mathrm{ml} \mathrm{TNF} \alpha$ containing CM for $4 \mathrm{wk}$. The concentrations were adjusted by diluting the CM using RPMI 1640 medium. R1881 (10 nM) treatments were performed $24 \mathrm{~h}$ prior to CM treatments and kept together until harvesting.

\section{Transfections}

The NKX3.1 open reading frame (ORF) was amplified using the following primers: primer F, GGATCCATGCTCAGGGTTCCGGAGCCG and primer R, GAATTCGGTTGTCACCTGAGCTGGCATTA and subsequently cloned into a pcDNA4/HisMax-TOPO (Invitrogen) vector according to the manufacturer's recommendations. Transfections were performed using FuGENE HD transfection reagent (Roche, Mannheim, Germany) for $24 \mathrm{~h}$. Briefly, $4 \times 10^{5}$ cells were seeded in 6 - $\mathrm{cm}$ plates and were propagated the next day with serum-free medium. The mix was prepared by adding $3 \mu \mathrm{l}$ transfection reagent into $100 \mu \mathrm{l}$ serum-free medium and incubating for $5 \mathrm{~min}$ at RT, $1 \mu \mathrm{g}$ DNA was then added to the mix and incubated for $15 \mathrm{~min}$. The mix was applied to the cells dropwise. After $6 \mathrm{~h}$ of incubation, fresh RPMI medium containing $2 \times$ FBS and antibiotics was added to the cells and incubated for an additional $18-42 \mathrm{~h}$.

Measurement of Reactive Oxygen Species Using DCFH

LNCaP cells $\left(10^{5}\right)$ were seeded in 6 -cm plates. The treatments were performed as described above, and the cells were collected into $15 \mathrm{ml}$ Falcon tubes using trypsin-EDTA. The tubes were centrifuged at $200 \mathrm{~g}$ for $5 \mathrm{~min}$, and the pelleted cells were washed and resuspended in PBS. The cells were incubated with DCFH-DA (2' $7^{\prime}$ - dichlorodihydrofluorescein diacetate, Sigma, UK; $10 \mu \mathrm{M}$ ) for $20 \mathrm{~min}$ at $37^{\circ} \mathrm{C}$. After incubation, the cells were washed and resuspended in PBS and the cells were analyzed immediately using a FacsAria I flow cytometer (BD Biosciences, San Diego) within the FITC channel.

\section{Antibodies}

The antibodies were purchased from the manufacturers as follows: the NFкB (p65), p-NFкB (p-p65), IkB, MMP9, p53, caspase-3, and MDM2 antibodies were purchased from Cell Signaling, Inc., Danvers, $\mathrm{MA}$; the $\gamma \mathrm{H} 2 \mathrm{AX}^{(\mathrm{S139})}$ and AR antibodies were obtained from Millipore, USA; the MMP8, Ubiquitin, PSA, p21, PARP1, pH3 ${ }^{(\mathrm{S} 10)}$, cytochrome C, $\mathrm{pAKT}^{(\mathrm{S} 473)}$, and NKX3.1 (T19X) antibodies were obtained from Santa Cruz, Inc., Santa Cruz, CA; and the GAPDH antibody was purchased from Ambion, USA. Dr. F. Saatcioglu, University of Oslo, provided the NKX3.1 custom antibody. The HRP-anti-mouse and HRPanti-rabbit secondary antibodies were purchased from Amersham, UK and used as recommended.

\section{Cell Lysis, Protein Extraction, and Blotting}

For protein extraction, cells were grown in $6-\mathrm{cm}$ plates (Sarstedt, Nümbrecht, Germany) and washed once with PBS prior to cell lysis. Next, $250 \mu$ l icecold modified RIPA buffer (10 mM Tris $\mathrm{Cl}$ (pH 8.0), $1 \%$ Triton $\mathrm{X}-100,0.1 \%$ SDS, $0.1 \% \mathrm{Na}$ deoxycholate, $1 \mathrm{mM}$ EDTA, $1 \mathrm{mM}$ EGTA, and $140 \mathrm{mM} \mathrm{NaCl}$ ) containing both protease and phosphatase inhibitors was added to the plates, and the cells were then collected into eppendorf tubes using a cell scraper. The lysates were sonicated for $20 \mathrm{~s}$ (25\% power, 0.5 cycles), centrifuged at $12,000 \mathrm{~g}$ for $10 \mathrm{~min}$ at $4^{\circ} \mathrm{C}$, and the cleared supernatants were transferred into new tubes. The protein concentration was determined using a BCA assay (Sigma). Western blots were performed under standard conditions using $50 \mu \mathrm{g}$ of protein lysate per lane. First, the proteins were separated on a 10-12\% SDS-PAGE gel and transferred to a PVDF membrane (Amersham, UK) using a wet transfer blotter. The PVDF membrane was blocked with $5 \%$ dry milk in TBS-T (Tris-BorateSaline solution containing $0.1 \%$ Tween 20), and then primary and secondary antibody incubations were performed using TBS-T containing $0.5 \%$ dry milk or $5 \%$ BSA at RT for $1 \mathrm{~h}$ or at $4{ }^{\circ} \mathrm{C}$ overnight. The membranes were developed using ECL plus reagent (Amersham, UK) for $5 \mathrm{~min}$ and were photographed using Kodak X-Ray films in a dark room.

Immunoprecipitation

Protein lysates $(500 \mu \mathrm{g})$ were subjected to immunoprecipitation using $2 \mu \mathrm{g}$ NKX3.1 or AR antibody at $4{ }^{\circ} \mathrm{C}$ overnight. The antigen-antibody complexes were collected after incubation with $20 \mu \mathrm{l}$ Protein A/G plus agarose (Santa Cruz, Inc.) for $1 \mathrm{~h}$ at $4^{\circ} \mathrm{C}$. After centrifugation at $4,000 \mathrm{~g}$ for $5 \mathrm{~min}$, the pellets were washed with $500 \mu$ l modified RIPA buffer five times. The collected beads were resuspended in $20 \mu l$ RIPA buffer, and one half of each sample was used for the SDS-PAGE run.

\section{WST1 Proliferation Assay}

LNCaP $\left(5 \times 10^{3}\right)$ cells were seeded and grown in 96-well plates for various time points. At the end of each treatment, WST1 (1:10 final dilution) cell proliferation reagent (Roche Cat No:05015944001) was added to the cells, and the cells were incubated for an additional $3 \mathrm{~h}$. At the end of the incubation, an absorbance at 450 and $690 \mathrm{~nm}$ reference wavelengths were used to measure the optical density to calculate the growth rate.

\section{Flow Cytometry and Analysis}

The cell cycle distribution was analyzed via flow cytometry with a FACSCanto (BD Biosciences) and the FacsDiva 5.0.3 analysis software. Briefly, the cells were resuspended in PBS and fixed with 100\% ethanol (cold) applied in a dropwise manner. RNase 
$(20 \mu \mathrm{g} / \mathrm{ml})$ treatment for $30 \mathrm{~min}$ at $37^{\circ} \mathrm{C}$ was followed by propidium iodide $(100 \mu \mathrm{g} / \mathrm{ml})$ staining $1 \mathrm{~h}$ at RT. After analysis, the cell cycle phases were plotted as histograms (mean values).

Total RNA Isolation and cDNA Preparation

Total RNA was isolated from cultured LNCaP cells using an RNeasy kit (Qiagen, CA), and the yield was calculated using absorbance readings at 260/ $280 \mathrm{~nm}$. Additionally, cDNA synthesis was performed using an $\mathrm{RT}^{2}$ First Strand cDNA Kit (SABiosciences, Valencia, CA) for the PCR array and an Omniscript RT Kit (Qiagen, CA) for other RT-PCR experiments as recommended by the manufacturers.

Real Time PCR

To examine the gene expression levels; quantitative RT-PCR was performed using a SYBR Green PCR kit and the LC480 PCR system (Roche). The relative abundance of each transcript was calculated using a comparative cycle of threshold (CT) method with GAPDH as an invariant control. The primers utilized include NKX3.1 forward: TCTATCAGCATCTGACAGGTGAA, NKX3.1 reverse: AGCAGGGTTTGTTATGCATGTAG, PSA forward: GCAGAGTGACATGTGCTGGA, PSA reverse: CTTGGCTCACAGCCTTCT, KLK4 forward: CTCGCTAACGACCTCATGCT, KLK4 reverse: CAGCACGGTAGGCATTCTG, GPX2 forward: CAGTCTCAAGTATGTCCGT, GPX2 reverse: AGGCTCAATGTTGATGGT, GAPDH forward: CATTGCCCTCAACGACCACTTT, and GAPDH reverse: GGTGGTCCAGGGGTCTTACTCC.

\section{Gene Expression Array}

A 96-well PCR array (SABiosciences, Inc., cat. no.: PAHS065) was used to analyze the gene expression profile of CM-treated cells (2, 4, and $24 \mathrm{~h}$ ) compared with controls. Briefly, cDNA (50 ng/well) was prepared from samples, added to the $\mathrm{RT}^{2}$ SYBR Green Master mix and distributed into the wells. The PCR reactions were performed according to the manufacturer's recommendations, and the results were analyzed using the comparative cycle of threshold (CT) method with four different genes (B2M, HPRT1, RPL13A, and GAPDH) as invariant controls.

\section{Neutralization}

Polyclonal TNF- $\alpha$ antibody ( $2 \mu \mathrm{g}$; Cell signaling) was added to either RPMI 1640 medium or CM (containing $500 \mathrm{pg} / \mathrm{ml} \mathrm{TNF}-\alpha$ ) and incubated at $4^{\circ} \mathrm{C}$ overnight with rotation. The cells were then treated with either neutralized or control medium for $6 \mathrm{~h}$. Immunoblot analysis of the NKX3.1, AR and GAPDH expression levels was performed using specific antibodies.

NFкB Luciferase Reporter Assay

Cells $\left(5 \times 10^{5}\right)$ were seeded in 6 -cm culture plates. Negative and positive control vectors $(100 \mathrm{ng} / \mathrm{ml})$, and NFкB (100 and $250 \mathrm{ng} / \mathrm{ml}$ ) reporter (Cignal Reporter Assay kit, SABiosciences) were transfected as described above for $24 \mathrm{~h}$. Next, the cells were treated with CM for $4 \mathrm{~h}$, and then washed with PBS and collected with passive lysis buffer. To measure luciferase activity, a dual-luciferase reporter assay kit (Promega, Mannheim, Germany) was used according to manufacturer's protocol.

\section{Nuclear-Cytoplasmic Fractionation}

The cells were rinsed, scraped into cold PBS and then centrifuged at $300 \mathrm{~g}$ for $5 \mathrm{~min}$. The pellets were suspended in $500 \mu \mathrm{l}$ buffer A (50 mM HEPES pH 7.4, $10 \mathrm{mM} \mathrm{KCl}, 1 \mathrm{mM}$ EDTA, $1 \mathrm{mM}$ EGTA, and $1 \mathrm{mM}$ DDT; supplemented with protease and phosphatase inhibitors) and incubated on a rotator for $30 \mathrm{~min}$. Next, the samples were centrifuged at $4,000 \mathrm{~g}$ for $30 \mathrm{~min}$, and the supernatant (cytoplasmic extract) was collected. The cell pellet was washed four times with buffer $\mathrm{A}$ and centrifuged again at $4,000 \mathrm{~g}$ for 5 min. After washing, the pellet was resuspended in $500 \mu \mathrm{l}$ buffer B (50 mM HEPES pH 7.4, 1 mM EDTA, $1 \mathrm{mM}$ EGTA, $400 \mathrm{mM} \mathrm{KCl}$, and $0.5 \%$ Triton X-100; supplemented with protease and phosphatase inhibitors) and incubated on a rotator for $30 \mathrm{~min}$. Centrifugation was performed at 14,000 $\mathrm{g}$ for $30 \mathrm{~min}$, and the supernatant (nuclear extract) was collected. All incubations and centrifugations were performed at $4^{\circ} \mathrm{C}$.

\section{Statistics}

The Student's t-test was applied to assess the statistical significance between pairs when necessary.

\section{RESULTS}

To examine whether macrophage infiltration during inflammation is associated with prostate cancer, we established a model to investigate the involvement of inflammation-mediated cytokines in prostate carcinogenesis $[6,9,18]$. To verify the model, we examined, first the NFкB activation following conditioned medium $(\mathrm{CM})$ treatment, and second the ROS mediated effects on cell growth upon inflammation. Furthermore, we also analyzed the uncontrolled proliferation of prostate cells following the abrogation of AR and p53 signaling upon CM treatment in dose and time course studies.

\section{U937 Cells Differentiate Into Macrophages and Produce Cytokines}

As a sign of macrophage differentiation, U937 cells generate clumps and develop adhesion after treatment with varying concentrations of phorbol acetate (PMA) in culture. Therefore, PMA treatment was used to induce the differentiation of the U937 monocyte cell line into macrophages, and the clumps were subsequently followed (Figure 1A). Afterward, differentiated cells were washed and LPS 
A
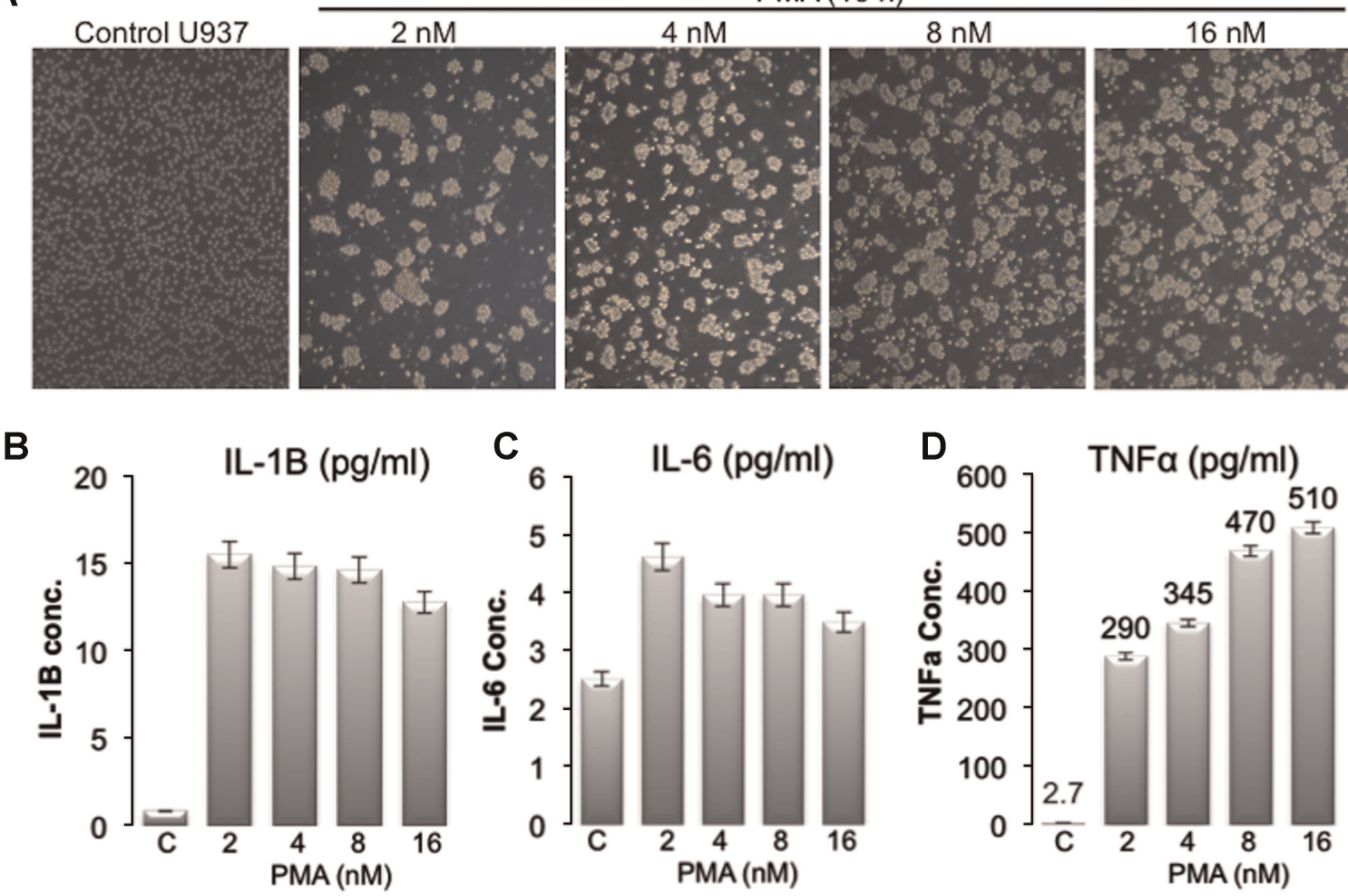

Figure 1. (A) U937 cells form aggregates upon PMA treatment (2-16 nM for $16 \mathrm{~h}$ ) and differentiate into macrophages. These cells produce cytokines after induction with LPS $(10 \mathrm{ng} / \mathrm{ml})$. Secreted cytokines levels are presented. (B) IL1B, (C) IL-6, and (D) The TNF $\alpha$ secreted from differentiated cells was measured via ELISA, and the concentrations are given in histogram plots. The measurements were performed for every individual experiment and were reproducible. The error bars show the standard deviations (SD) for each cytokine concentration.

(10 ng/ml) was administered to induce cytokine secretion. After $24 \mathrm{~h}$, the conditioned medium (CM) was collected, filtered, and the cytokine levels were measured using ELISA assay. TNF $\alpha$ level was found to be significantly higher (at $510 \mathrm{pg} / \mathrm{ml}$ at $16 \mathrm{nM}$ PMA induction) than the control with PMA only in U937 cells, while IL1 $\beta$ and IL-6 levels were marginally increased (12.8, and $4.0 \mathrm{pg} / \mathrm{ml}$; Figure 1B-D). As the induced IL1 $\beta$ and IL- 6 concentrations remained lower than the normal serum levels [19] (TNF $\alpha$ :

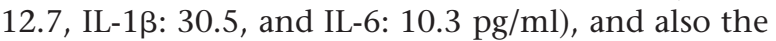
basal levels in LNCaP cells (IL1ß [30.7 $\pm 5.7 \mathrm{pg} / \mathrm{ml}]$, IL-6 $[17.1 \pm 0.3 \mathrm{pg} / \mathrm{ml}]$, and TNF $\alpha[13.6 \pm 3.0 \mathrm{pg} /$ $\mathrm{ml}]$ ), the stimulated $\mathrm{TNF} \alpha$ concentration (almost 190-fold of control; $P<0.01$ ) was used as a measure of inflammation strength to adjust the CM concentration for LNCaP cells.

CM Treatment Enhanced MMP9 Expression Mediated by NFkB Translocation

$\mathrm{CM}$ was used to feed LNCaP cells to facilitate a dose-dependent and controlled inflammatory microenvironment in cell culture with varying TNF $\alpha$ concentrations $(62.5,125,250$, and $500 \mathrm{pg} / \mathrm{ml})$. We found that LNCaP cells displayed a distinguished morphology after 3-6 h of CM treatment (Figure 2A), as the cells had a tendency to form clumps rather than spreading out. Next, we examined the effect of the CM exposure time $(2,4,6,12$, and $24 \mathrm{~h}$ ) to determine the highest levels of NFkB phosphorylation and IkB degradation in LNCaP cells. Accordingly, $\mathrm{CM}$ exposure led to an increase in $\mathrm{IkB}$ degradation beginning at $4 \mathrm{~h}$, thereby resulting in a consequent a peak level of $\mathrm{NF \kappa}^{(\mathrm{S} 536)}$ phosphorylation at $6 \mathrm{~h}$ (Figure 2B). We found that the nuclear translocation of $\mathrm{NF \kappa B}$ increased in both cell lines following CM treatment (Supplementary Figure 1A). Furthermore, we found that the expression levels of both the active (p84) and inactive (p92) forms of the NFкB transcriptional target, MMP9, increased following $12 \mathrm{~h}$ of CM treatment. MMP8 expression levels were also elevated following the $6 \mathrm{~h}$ treatment in our inflammation model. Moreover, using reporter assay we found that $\mathrm{CM}$ treatment induced $\mathrm{NF \kappa B}$ transactivation hundred fold compared with the control reporter (Figure 2C). Taken together, these data suggest that NFאB nuclear translocation and subsequent transactivation occurs in prostate cells as an early response to cytokine exposure. 
A

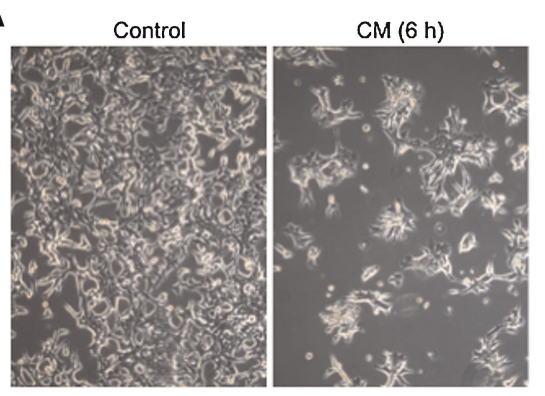

B

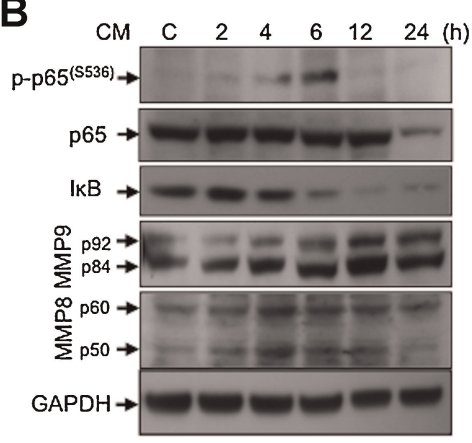

C

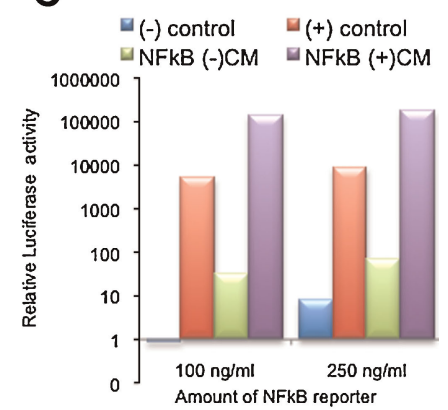

D

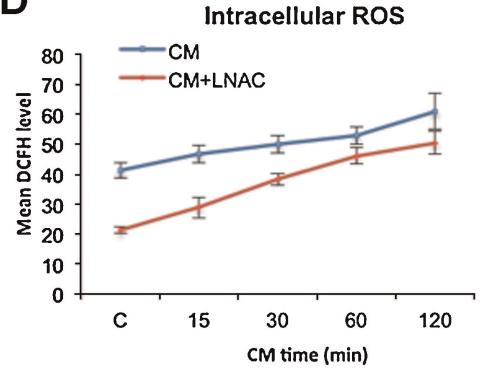

E

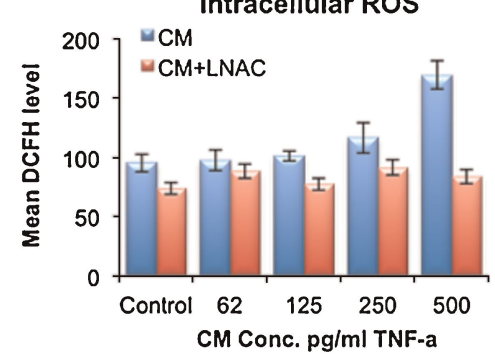

$\mathbf{F}$

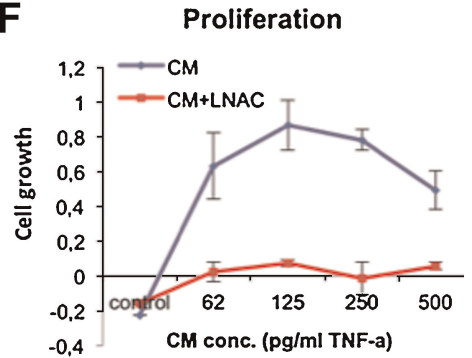

Figure 2. (A) Morphological alterations were observed in prostate cells when LNCaP cells were treated with conditioned media $(500 \mathrm{pg} / \mathrm{ml}$ TNF $\alpha$ ) for $6 \mathrm{~h}$ (magnification $\times 10)$. (B) NFKB signaling was activated by $C M$, as presented here in a time course study assessed by Western blot. An increased expression of MMP9 was observed as a result of $\mathrm{IkB}$ degradation and $\mathrm{NF \kappa B}$ transactivation. Additionally, activation of the innate immune response led to an increase in MMP8 expression. GAPDH expression levels are shown to demonstrate the equal loading of lysates. (C) NFKB activity increased

\section{ROS-Mediated Proliferation Is Suppressed by the} Antioxidant L-NAC

Many cytokines and growth factors generate ROS as signaling secondary messengers [2]. This property contributes to the progression of cancer by adding further DNA alterations to the genome of a cell population during inflammation. Therefore, intracellular ROS levels were examined in dose and timecourse studies in this report. We found that the ROS levels correlated with increasing $\mathrm{TNF} \alpha$ concentrations, which can be significantly abrogated using the antioxidant L-NAC in LNCaP cells (Figure 2D,E). Cell growth was analyzed using WST assay, and we found that the proliferation rate increased with $\mathrm{CM}$ treatments at 62.5 and $125 \mathrm{pg} / \mathrm{ml}$, whereas the proliferation rate decreased with $\mathrm{CM}$ treatments containing $250 \mathrm{pg} / \mathrm{ml} \mathrm{TNF} \alpha$ and at higher TNF $\alpha$ concentrations (Figure 2F). Overall, the data suggest that the cells respond to cytokines differently above physiological doses longer than $12 \mathrm{~h}$ of exposure.

CM Treatment Results in the Upregulation of ProliferationAssociated Genes

Based on the gene expression analysis performed following the 2, 4, and $24 \mathrm{~h} \mathrm{CM}$ treatments, considerable alterations in the expression levels of upon CM treatment for $4 \mathrm{~h}$, as shown using a NFkB reporter assay. (D) The intracellular ROS levels increased in time with CM treatment $(500 \mathrm{pg} / \mathrm{ml}$ TNF $\alpha)$, (E) the intracellular ROS levels increased with increasing TNF $\alpha$ concentrations $(62,125,250$, and $500 \mathrm{pg} / \mathrm{ml})$ in $\mathrm{LNCaP}$ cells. The treatments were performed in the presence or absence of antioxidant L-NAC for $2 \mathrm{~h}$ and were measured using DCFH dye via flow cytometer. (F) The increasing doses of TNF $\alpha$ containing CM influenced the proliferation of LNCaP cells, as shown in the presence or absence of L-NAC for $24 \mathrm{~h}$.

antioxidant defense genes were observed. Not surprisingly, a significant $(P<0.05)$ upregulation of PXDNL, MBL2, MPO, PTGS1, and NCF1 was observed, while SEPP1 was found to be downregulated, which depended on the CM concentration and was consistent with the levels of NFkB activation (Figure 3A). These expression data confirm that the response is generated due to in vitro inflammation in prostate cells. Furthermore, the expression of the antioxidant defense genes aldehyde oxidase 1 (AOX1), diacylglycerol kinase kappa (DGKK), glutathione peroxidase 3 (GPX3) and glutathione peroxidase 7 (GPX7) were also found to be upregulated in LNCaP cells following CM treatment in comparison with controls (Figure 3B). As the time-dependent changes are consistent, we demonstrated that CM exposure enhanced keratin 1 (KRT1) expression at more than 200-fold that of the control in $4 \mathrm{~h}$ (Figure 3C). Moreover, prostaglandin-endoperoxide synthase 2 (PTGS2) expression levels were also increased up to 60 -fold compared with the control at following the $24 \mathrm{~h} \mathrm{CM}$ treatment. The expression levels of tumor differentiation related factor dual oxidase 2 (DUOX2) [20], lung adenocarcinoma proliferation and migration promoting factor apolipoprotein $\mathrm{E}$ (APOE) and the tumor growth driving peroxide, glutathione peroxidase 2 (GPX2) [21,22], 
A

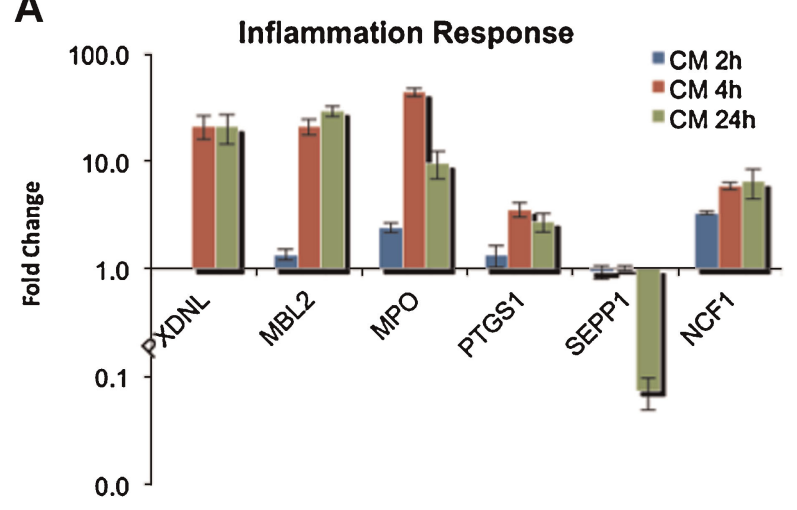

B

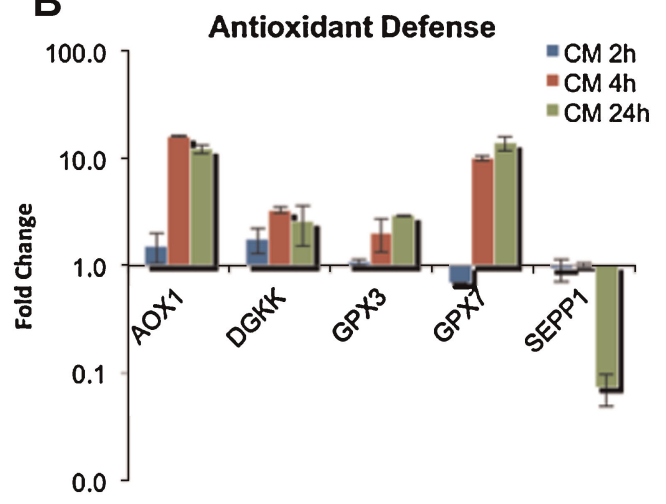

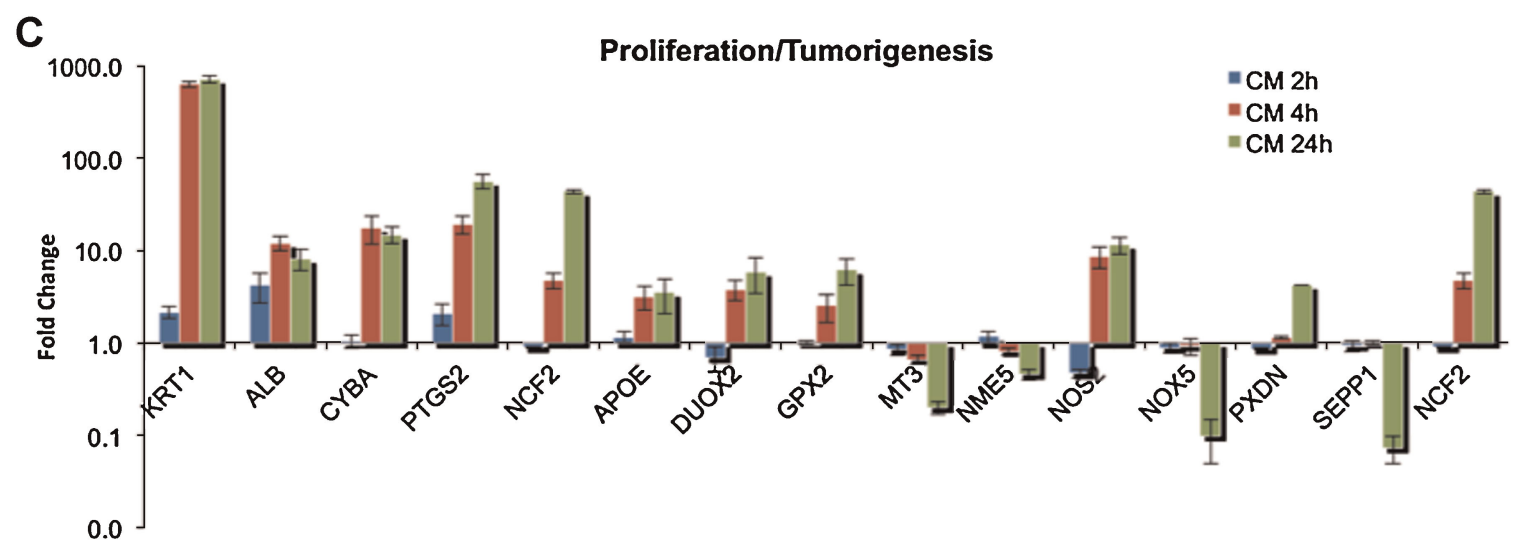

Figure 3. The expression levels of oxidative stress and antioxidant defense genes are shown after the treatment of LNCaP cells with CM $(2,4$, and $24 \mathrm{~h})$. The inflammation response (A), antioxidant defense (B), and the genes contributing to proliferation and/or tumorigenesis (C) are displayed here. PCR array studies were performed three times and $P$ values were calculated $(<0.05)$. The error bars represent the SD for each histogram plot.

were also increased by CM treatment. As MT-3 and SEPP1 were downregulated by CM treatment, the deregulated expression of the antioxidant defense genes described above could be associated with cell growth and proliferation and are significantly altered upon CM exposure (Figure 3C). Taken together, our in vitro prostate inflammation model mimics the inflammation-mediated changes in gene expression.

Blocking Kinases Restores the CM-Mediated Loss of AR but not AR-Mediated Transactivation

A number of cellular processes control the growth and survival of prostate cancer cells to regulate the expression, stability and function of the AR and possibly circumvents the androgen requirement for AR transactivation $[23,24]$. Here, we examined the loss of the AR-mediated signaling during $\mathrm{CM}$ treatment via time course studies $(0,2,4,6,12$, and $24 \mathrm{~h})$ in prostate cells (Figure 4 and Supplementary Figure 1). AR and androgen responsive NKX3.1 expression levels were found to be reduced at $6 \mathrm{~h}$ (Figure 4A-C) with a complete loss at 12-24 h (Figure 4E,F) of CM exposure in LNCaP cells regardless of androgen, whereas only AR loss was evident in RWPE-1 cells (Supplementary Figure 1B). As these losses may be either transcriptional or associated with proteasomal degradation, the ubiquitination of both the AR and NKX3.1 was assessed in our studies. Thus, the highest levels of ubiquitination was observed with the $6 \mathrm{~h}$ of CM treatment, AR expression level was also found lower than that of the control cells (Figure 4A). Taken together, prostate cells rely on both androgens and the AR for controlled maintenance and survival; the data suggest that the treatment with $\mathrm{CM}$ containing high doses of $\mathrm{TNF} \alpha$ $(500 \mathrm{pg} / \mathrm{ml})$ contributes to the loss of AR signaling even at short exposures in acute inflammation model.

Furthermore, to investigate if the CM-mediated AR degradation can be suppressed, LNCaP cells were treated with Akt and CK2 kinase inhibitors (wortmannin and TBCA, respectively) in addition to $\mathrm{CM}$ treatments. Then, we found that both inhibitors partially restored the CM-mediated degradation of the AR at shorter exposures in the absence of 
A

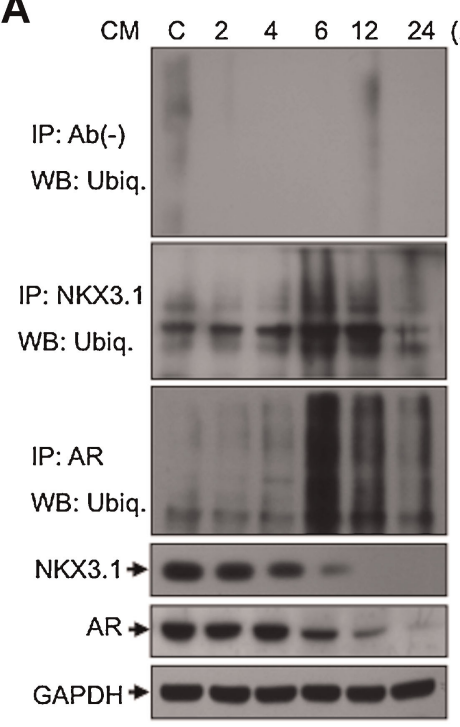

E

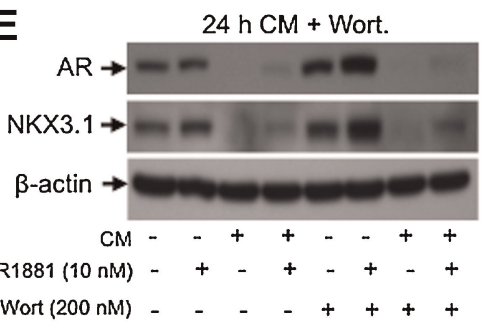

B

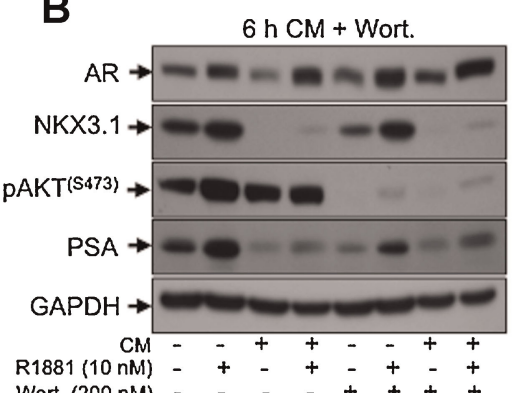

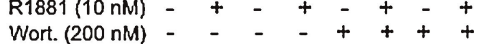

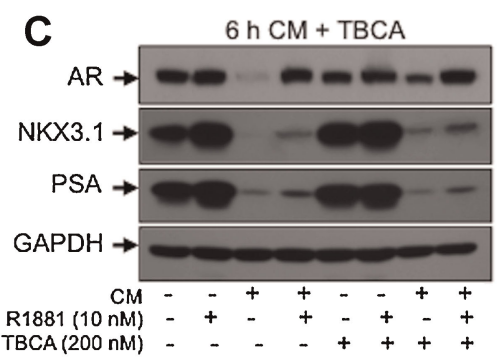

$\mathbf{F}$

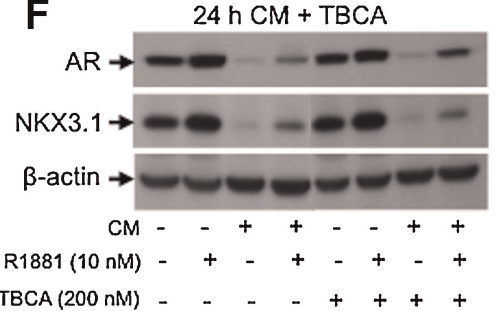

D

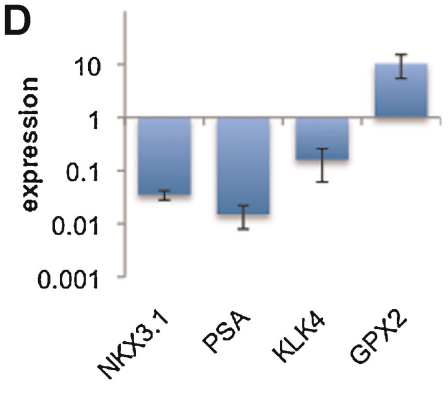

Figure 4. (A) The ubiquitination of AR and NKX3.1 are shown. (B) LNCaP cells were treated with wortmannin (200 nM) for $7 \mathrm{~h}$ (added onto cells $1 \mathrm{~h}$ prior to conditioned media) in the presence or absence of R1881 (10 nM) and CM (500 pg/ml TNF $\alpha)$ for $6 \mathrm{~h}$. The AR, NKX3.1, and PSA expression levels and the AKT ${ }^{(S 473)}$ phosphorylation level are displayed. (C) LNCaP cells were treated with 200 nM TBCA for $7 \mathrm{~h}$ in the presence or absence of R1881 (10 nM) and CM $(500 \mathrm{pg} / \mathrm{ml}$ TNF $\alpha$ ) for $6 \mathrm{~h}$. The PSA and NKX3.1 expression levels were given the loss of $A R$ transactivation function. (D) AR-mediated transcription (PSA, KLK4, and NKX3.1 transcription levels) was downregulated by $24 \mathrm{~h}$ CM exposure as assessed by RT-PCR. GPX2 expression was also assessed as a non AR-mediated expression control. LNCaP cells were treated with either wortmannin (200 nM; E) or TBCA (200 nM; F) for $25 \mathrm{~h}$ (added onto cells $1 \mathrm{~h}$ prior to CM) in the presence or absence of R1881 (10 nM) and CM $(500 \mathrm{pg} / \mathrm{ml}$ TNF $\alpha$ ) for $24 \mathrm{~h}$. The AR and NKX3.1 expression levels are shown. Western blots were performed at least three times. androgen (Figure 4B,C). Accordingly, AR-mediated transactivation was also verified with the analysis of PSA expression (compared with GAPDH expression levels) following CM treatment (Figure $4 \mathrm{~B}, \mathrm{C}$ ) in the presence of androgens (R1881), and found that the use of wortmannin restored the AR expression, but not PSA expression. When PSA, KLK4, and NKX3.1 mRNA expressions were examined, it was found that $\mathrm{CM}$ treatment downregulated the expressions at $24 \mathrm{~h}$ (Figure 4D). As the specific CK2 and Akt inhibitors restored the degradation of the AR but not the transactivation, these results suggest that inflammation-mediated AR signaling is abrogated even at very short CM exposures. Further, the CM exposure time was extended to $24 \mathrm{~h}$ and observed that the use of kinase inhibitor wortmannin could not sustain the inhibitory effect on AR and NKX3.1 degradation (Figure 4E,F), implied that this can be related to short half-life of wortmannin in cell culture.

\section{AR Degradation Is Mediated by TNF $\alpha$}

To validate the TNF $\alpha$-mediated effects, the degradation of AR and NKX3.1 was neutralized using TNF $\alpha$ specific polyclonal antibody, and the restoration of expression was examined. Intriguingly, consistent with the results in kinase inhibitors (Figure 4), TNF $\alpha$ antibody treatment restored the AR expression (Supplementary Figure 2A, lanes 3 and 4) over the basal levels in controls (lanes 1 and 2) regardless of CM treatment. Furthermore, recTNF $\alpha$ induction was performed in LNCaP cells for 3, 6, and $24 \mathrm{~h}$, and immediate loss of NKX3.1 and degradation of AR were also observed. As, the initial increase in AR expression evolved into a significant decrease at longer exposures demonstrates that AR 
A
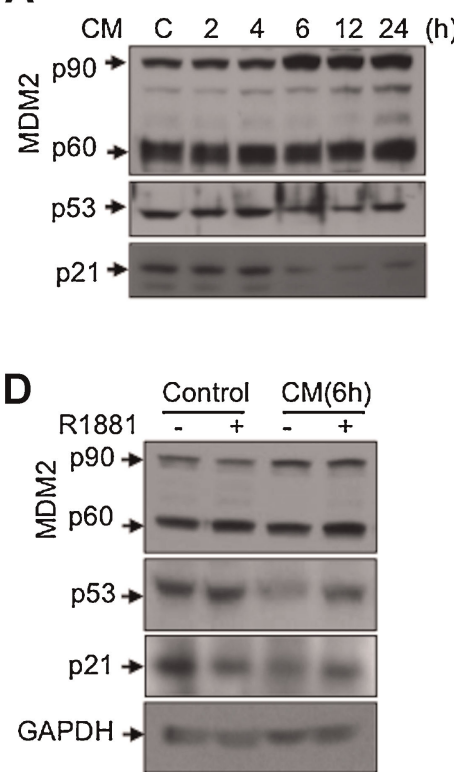

$B$

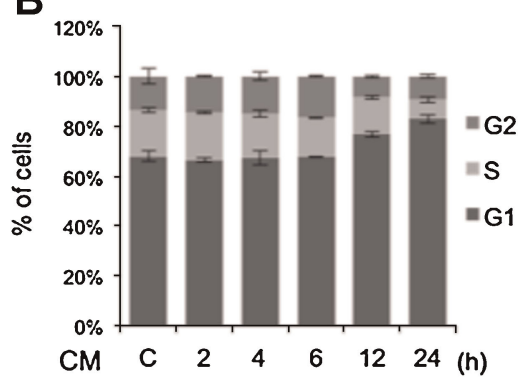

E

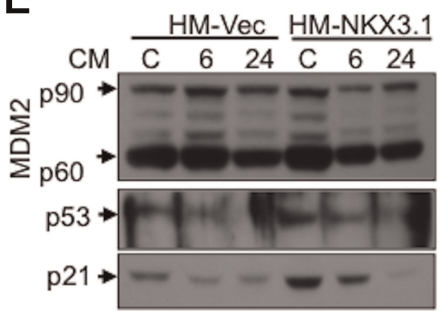

C

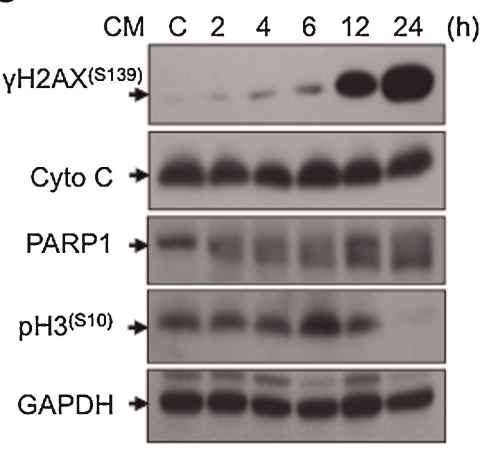

$\mathbf{F}$

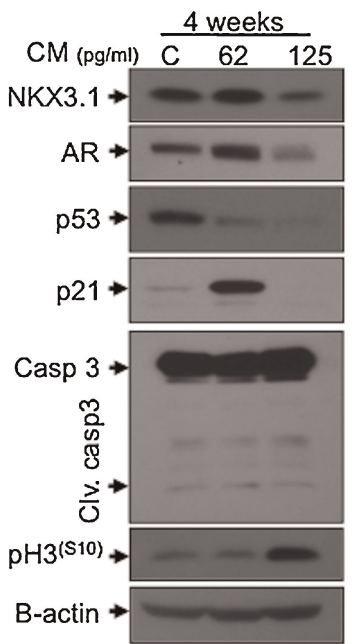

Figure 5. (A) MDM2 p90 expression levels increased with the concurrent loss of $p 53$. The subsequent downregulation of p21 is shown following CM treatment of $6 \mathrm{~h}$ or more. (B) Cell cycle phases are displayed via histogram. The number of cells in the $G 1$ phase increased after $6 \mathrm{~h}$, while the cell count in the $\mathrm{S}$ phase decreased by increasing the exposure time $(\mathrm{C})$ Inflammation contributes to DNA damage by enhancing $H 2 A X^{\text {(S139) }}$ phosphorylation in a time-dependent manner. $\mathrm{H}^{(\mathrm{S} 10)}$ phosphorylation increased and reached the peak level at $6 \mathrm{~h}$, while apoptosis was not induced. Cytochrome C levels remained unchanged, whereas PARP1 and $\gamma H 2 A X^{(S 139)}$ degradation levels increased upon CM exposure. These results show that DNA damage increases with p53 loss. (D) The loss of p53 following CM exposure was restored via androgen administration, and NKX3.1

and NKX3.1 degradations are mediated by TNF $\alpha$ in prostate cells, and the loss of expression is likely independent from AR transcriptional control.

Chronic Exposure to CM Contributes to the Loss of p53 Transactivation

During CM exposure in the time course studies $(0$, $2,4,6,12$, and $24 \mathrm{~h}$ ), a marginal MDM2 stabilization was observed at the p90 level without an alteration in the p60 levels (degradation of MDM2; Figure $5 \mathrm{~A}$ ). This subsequently resulted in a decrease in both p53 and p21 expression levels. However, cell cycle analysis results using ModFit [25] showed that there was no change until the $6 \mathrm{~h}$ of CM treatment, whereas the G1 population increased with the 12 and $24 \mathrm{~h}$ treatments (Figure $5 \mathrm{~B}$ and expression (E) subsequently activated p21 transcription. (F) Chronic inflammation (CM treatment containing 62.5 and $125 \mathrm{pg} / \mathrm{ml}$ TNF $\alpha$ during $4 \mathrm{wk}$ ) leads to a decrease in both NKX3.1 and AR protein levels. Additionally, apoptotic control was abrogated as a result of p53 protein loss. p21 expression was maintained with $62.5 \mathrm{pg} / \mathrm{ml}$ TNF $\alpha / C M$; however, it is completely downregulated with $125 \mathrm{pg} / \mathrm{ml}$ TNF $\alpha / C M$. Ultimately, no changes were observed in caspase-3 cleavage. $\mathrm{pH} 3^{(\mathrm{S} 10)}$ revealed increased mitosis following $125 \mathrm{pg} / \mathrm{ml}$ TNF $\alpha /$ CM-induced chronic inflammation. (G) The schema summarizes the mechanism involving MDM2 and p53, which are negatively influenced by the inflammatory microenvironment and restored in the presence of androgen and NKX3.1 expression.

Supplementary Figure 3). These data suggest that the loss of p21 function at G1 arrest is mediated by p53 and facilitated by AR signaling, which were abrogated by CM treatment in LNCaP cells. Additionally, the loss of p53 expression contributed to an increase in DNA damage, which was demonstrated by an increase in H2AX phosphorylation, while cytochrome $\mathrm{C}$ levels remained unchanged (Figure 5C). However, the administration of androgen (R1881) led to an increase in the degradation of MDM2 (p60), regardless of the CM treatment, and maintained p53 stabilization in LNCaP cells. As the high concentration of $\mathrm{CM}$ treatment was performed for $6 \mathrm{~h}$, the partial restoration of p53 by androgen administration was confirmed by assessing the p21 expression levels (Figure 5D). Ectopic NKX3.1 
expression also restored p53 transactivation during CM treatment, which was also confirmed with by the increasing p21 expression levels (Figure 5E). Thus, androgens restore p53 transactivation and its growth regulatory function via crosstalk with AR, and this interaction presumably suppresses the development of error-prone phenotype in prostate cells.

As the link in between chronic inflammation and tumorigenesis has already been established in many tumors, chronic inflammation was also studied using LNCaP cells. AR and NKX3.1 loss were observed until 4 wk of CM exposure (CM containing $125 \mathrm{pg} / \mathrm{ml} \mathrm{TNF} \alpha$ ). Accordingly, we found that apoptotic regulation could not be maintained via decreased p53 levels, which was confirmed with the unchanged caspase- 3 cleavage upon $\mathrm{CM}$ exposure. Furthermore, at lower doses of CM $(62 \mathrm{pg} / \mathrm{ml}$ $\mathrm{TNF} \alpha$ ), p21 expression levels increased, whereas $\mathrm{H} 3^{(\mathrm{S} 10)}$ (mitosis marker) phosphorylations were significantly depleted. These data suggest that the cells arrest and do not proliferate at lower doses of CM treatment. Consistently, at higher concentrations of $\mathrm{CM}$, which resulted in an increase in $\mathrm{H}^{(\mathrm{S} 10)}$ phosphorylation levels, the complete loss of p53 and p21 was observed (Figure 5F). Thus, we have shown that androgen administration partially restored p53 function and p21 expression levels, while NKX3.1 expression considerably restored p53 function and p21 expression levels, which were abrogated by inflammatory cytokines in prostate cells (Figure 5G).

\section{DISCUSSION}

Previous reports have demonstrated that the inflammatory microenvironment contributes to cancer initiation, which can be facilitated via major growth regulatory pathways, such as Akt and p53 as well as $\mathrm{AR}$ in prostate tissue $[4,5]$. As both $\mathrm{AR}$ expression and signaling are extensively studied in prostate cancer, AR is a well-recognized maintenance factor, requires for the regulated growth of prostate cells [13]. Here, we investigated the molecular alterations that may facilitate prostate carcinogenesis, and examined these responses by simulating the inflammatory microenvironment in vitro [19]. In this study, we have shown that CM exposure results in a profound increase in the degradation of $\mathrm{I}_{\kappa} \mathrm{B}$ and subsequent $\mathrm{NF \kappa B}$ transactivation following its nuclear translocation. Therefore, CM treatment establishes an inflammatory microenvironment in vitro and the basal cellular phenotype mimics the initiation of prostate carcinogenesis subsequent of $\mathrm{NF} \kappa \mathrm{B}$ activation in androgen responsive LNCaP cells.

To validate the model, a number of antioxidant genes including the GPX3, GPX7, KRT1, PTGS2, DUOX2, APOE, MT-3, SEPP1, and NOS2 were analyzed for expression and found that these factors are changing in expression in an agreement with previous studies [26-31]. As the deregulated expressions of antioxidant defense genes, such as reported above, are related to the cell growth and proliferation and is critically altered even at short exposures of CM treatments (Figure 3), we suggest that our in vitro inflammation model mimics the prostatic inflammatory atrophy (PIA), and the inflammationmediated gene expression changes in prostate cells. Further, the ROS levels were examined and the increase in ROS-mediated cell growth was suppressed with an antioxidant use. These results also imply that the ROS-mediated effects can be regulated by a scavenging mechanism in prostate cells, and this requires an intact maintenance factor, such as $A R$, to facilitate the androgen-regulated factor NKX3.1 expression.

Moreover, in a previous study, Culig et al. [32] have reported that the AR transactivation function is abrogated by administration of IL- $1 \beta$, where the PSA expression was also found downregulated. Further, in another report, Markowski et al. [14] have also shown that TNF $\alpha$ and IL-1 $\beta$ induced the loss of NKX3.1 via proteasomal degradation [14]. Since, these studies have extensively addressed the specific NKX3.1 phosphorylations and the AR turnover respectively, in another study, Khalili et al. [33] have demonstrated that the reduced expression of NKX3.1 significantly correlates with an increased expression of the proliferation marker, Ki67, in infected prostate lobes. In this model, they injected an uropathogenic Escherichia coli strain into mice using intraurethral inoculation to establish an in vivo prostate inflammation model. They also reported that AR expression was downregulated in these infected prostate luminal ducts; although, the expression levels remained detectable in all cases. As with the Nkx3.1 results, AR protein level was also retained in non-inflamed ducts adjacent to inflamed ducts. Since, it was demonstrated that AR expression was restored in epithelial cells when the inflammation was cleared [33], the transactivation function was not examined implied us that the retained expression of AR and NKX3.1 may not be functional for both prostate development and maintenance in infected prostate luminal cells [33]. Hence, the data in the previous reports strongly correlate with the CM-mediated AR and NKX3.1 degradation [13], which are demonstrated here, might be subsequent to abrogated antioxidant response during inflammation in a dose and time dependent manner.

The physiological level of $\mathrm{TNF} \alpha$ from blood of healthy donors was reported to be in the range of $0-67.6 \mathrm{pg} / \mathrm{ml}$ [34] and the IL-1 $\beta$ concentration included in $\mathrm{CM}$ remains lower than $\mathrm{LNCaP}$ intrinsic level. Thus, different concentrations of CM (up to $500 \mathrm{pg}$ of TNF $\alpha$ ) for 6 and $24 \mathrm{~h}$ were used in our studies. While, it is well known that the macrophage infiltration increases cytokine release [34], 

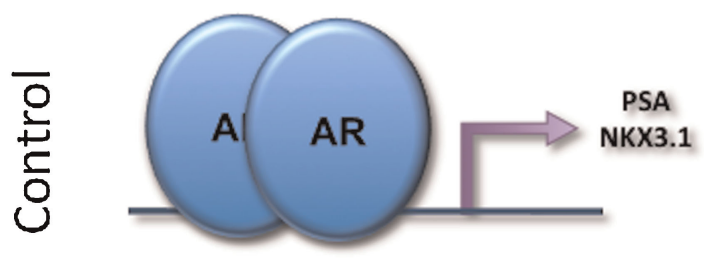

LNCaP

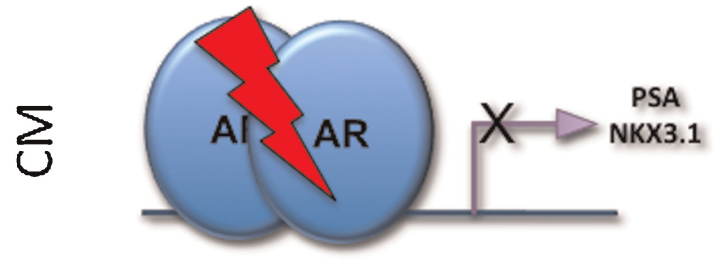

No response
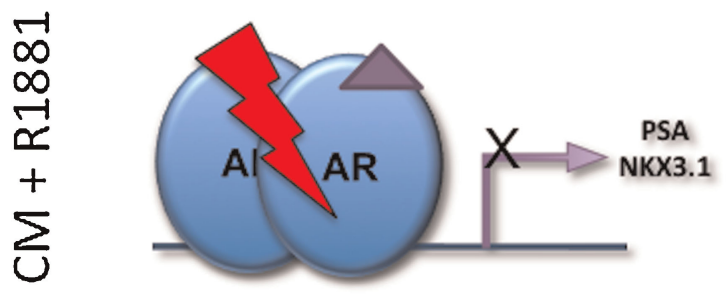

No response

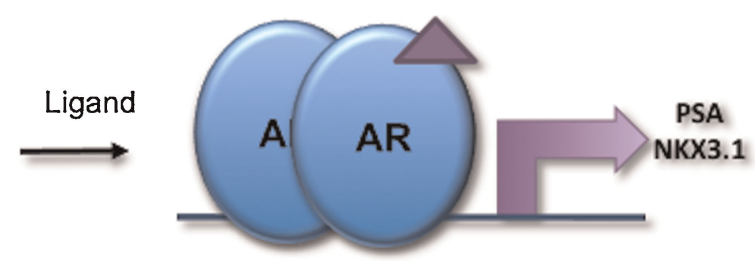

Androgen response

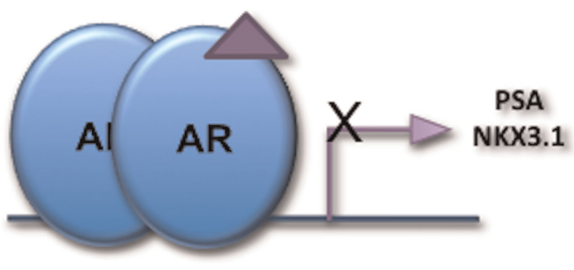

Abrogated response

\section{Wort.}

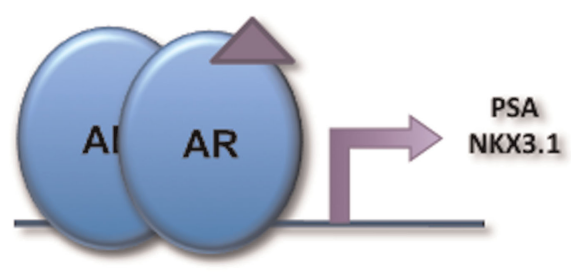

Androgen response

Figure 6. AR signaling is significantly altered due to the loss of AR in LNCaP cells following CM treatment. Akt inhibition restores both the AR expression and AR-mediated transactivation, whereas CK2 inhibition restores only the AR expression but not transactivation. Alterations are presented in a schema where the ligand (androgen; R1881) and wortmannin synergize the effect.

the TNF $\alpha$ concentration is expected to be remarkably high in these tissues. However, since a considerable degradation of AR and NKX3.1 was observed with aforementioned concentrations; therefore, much lower concentrations of TNF $\alpha(62.5,125$, and $250 \mathrm{pg} / \mathrm{ml}$ ) for longer exposures simulated a chronic inflammation in our studies. The NKX3.1 degradation might facilitate the proliferation during the early steps of prostate carcinogenesis by deregulating the expression of antioxidant defense genes. As the concentrations of recombinant cytokines used in previous studies were almost 100 times higher than the doses applied in our model $(40 \mathrm{ng} / \mathrm{ml}$ for both $\mathrm{TNF} \alpha$ and IL-1 $\beta$ ), one can conclude that the very low $\mathrm{TNF} \alpha$ exposure might result in the loss of ARmediated transactivation as well as ROS regulatory function in the cell that might facilitate the prostate cancer progression during inflammation.

Thus, AR-mediated transactivation is downregulated during inflammatory conditions, which results in the loss of prostate cell maintenance as an initial response. As the specific CK2 and Akt inhibitors may restore the degradation of the AR but not
AR-mediated transactivation in prostate cells, the findings obtained here suggest that inflammationmediated AR signaling is an important event and is abrogated even at short exposure to inflammatory cytokines, whereas the transactivation function of AR may not be restored exclusively by the recovery of AR expression (Figure 6). This result implies that other factors mediated by AR signaling may regulate prostate cell maintenance, which may also be required to retain AR function in prostate cells. Additionally, we suggest that ROS induces DNA damage and facilitates tumor progression by promoting genetic heterogeneity in prostate cells. As inflammation-mediated ROS contributes to the survival function of $\mathrm{NF \kappa B}$ and alters both the adherence and growth properties of prostate cells, its overall effect is reduced by the use of the antioxidant, L-NAC, in prostate cells. Thus, inflammationmediated ROS generation damages cellular genetic material and negatively influences prostate cell maintenance by degrading the major contributors of cell survival, such as AR, NKX3.1 and p53, in prostate cells. 
Taken together, macrophage infiltration during inflammation is an important contributor to prostate carcinogenesis, in which cytokines such as tumor necrosis factor- $\alpha$ (TNF $\alpha)$ function as proinflammatory cytokine and promotes carcinogenesis [6],[9],[18]. As a result of the TNF $\alpha$-mediated induction of NFkB signaling, the ROS-mediated effects result in an increase in the growth rate, which is deregulated by androgen signaling in prostate cells. However, p53 is also a key factor, as it is degraded via the MDM2-dependent pathway during the inflammation and must be functional to maintain high genome fidelity in these cells. Therefore, the abrogated AR and p53 response due to the CM treatments resulted in an increase in genetic heterogeneity at the inflammatory regions of prostate, where the error-prone phenotype develops. This mechanism requires extensive investigation in animal studies. Here, we report that the in vitro prostate inflammation model is a relevant and simple model that can be used to study molecular alterations, cell growth, AR-mediated transactivation and prostate cell maintenance upon inflammation.

\section{ACKNOWLEDGMENTS}

We would like to thank Dr. R. Schneider-Stock for providing the U937 cells. This research was supported by the Turkish Scientific and Technological Research Council (grants TUBITAK-106S200, -110S134), COST action BM0703 CANGENIN (TUBITAK108S288), and by Ege University internal funds granted to K.S.K.

\section{REFERENCES}

1. Hussain SP, Harris CC. Inflammation and cancer: An ancient link with novel potentials. Int J Cancer 2007;121:23732380.

2. Ushio-Fukai M. Compartmentalization of redox signaling through NADPH oxidase-derived ROS. Antioxid Redox Signal 2009;11:1289-1299.

3. Morgan MJ, Kim YS, Liu ZG. TNFalpha and reactive oxygen species in necrotic cell death. Cell Res 2008:18:343-349.

4. Reuter S, Gupta SC, Chaturvedi MM, Aggarwal BB. Oxidative stress, inflammation, and cancer: How are they linked? Free Radic Biol Med 2010;49:1603-1616.

5. Schetter AJ, Heegaard NH, Harris CC. Inflammation and cancer: Interweaving microRNA, free radical, cytokine and p53 pathways. Carcinogenesis 2010;31:37-49.

6. Khandrika L, Kumar B, Koul S, Maroni P, Koul HK. Oxidative stress in prostate cancer. Cancer Lett 2009;282:125-136.

7. Morgan MJ, Liu ZG. Crosstalk of reactive oxygen species and NF-kappaB signaling. Cell Res 2011;21:103-115.

8. Minelli A, Bellezza I, Conte C, Culig Z. Oxidative stress-related aging: A role for prostate cancer? Biochim Biophys Acta 2009;1795:83-91.

9. De Marzo AM, Platz EA, Sutcliffe $S$, et al. Inflammation in prostate carcinogenesis. Nat Rev Cancer 2007;7:256269.

10. Tam NN, Gao Y, Leung YK, Ho SM. Androgenic regulation of oxidative stress in the rat prostate: Involvement of $\mathrm{NAD}(\mathrm{P}) \mathrm{H}$ oxidases and antioxidant defense machinery during prostatic involution and regrowth. Am J Pathol 2003; 163:2513-2522.
11. Rokhlin OW, Taghiyev AF, Bayer KU, et al. Calcium/calmodulin-dependent kinase II plays an important role in prostate cancer cell survival. Cancer Biol Ther 2007;6:732-742.

12. Rokhlin OW, Scheinker VS, Taghiyev AF, Bumcrot D, Glover RA, Cohen MB. MicroRNA-34 mediates AR-dependent p53induced apoptosis in prostate cancer. Cancer Biol Ther 2008; 7:1288-1296.

13. Ouyang $X$, DeWeese TL, Nelson WG, Abate-Shen C. Lossof-function of Nkx3.1 promotes increased oxidative damage in prostate carcinogenesis. Cancer Res 2005;65:6773-6779.

14. Markowski MC, Bowen C, Gelmann EP. Inflammatory cytokines induce phosphorylation and ubiquitination of prostate suppressor protein NKX3.1. Cancer Res 2008;68:68966901.

15. Bieberich CJ, Fujita K, He WW, Jay G. Prostate-specific and androgen-dependent expression of a novel homeobox gene. J Biol Chem 1996:271:31779-31782.

16. Korkmaz KS, Korkmaz CG, Ragnhildstveit E, Kizildag S, Pretlow TG, Saatcioglu F. Full-length CDNA sequence and genomic organization of human NKX3A-Alternative forms and regulation by both androgens and estrogens. Gene 2000;260:25-36.

17. Korkmaz CG, Korkmaz KS, Manola J, et al. Analysis of androgen regulated homeobox gene NKX3.1 during prostate carcinogenesis. J Urol 2004;172:1134-1139.

18. Schetter AJ, Heegaard $\mathrm{NH}$, Harris CC. Inflammation and cancer: interweaving microRNA, free radical, cytokine and p53 pathways. Carcinogenesis 2009;31:37-49.

19. Jablonska E, Piotrowski L, Grabowska Z. Serum levels of IL$1 \mathrm{~b}, \mathrm{IL}-6, \mathrm{TNF}-\mathrm{a}, \mathrm{sTNF}-\mathrm{RI}$ and CRP in patients with oral cavity cancer. Pathol Oncol Res 1997;3:126-129.

20. Lacroix L, Nocera M, Mian C, et al. Expression of nicotinamide adenine dinucleotide phosphate oxidase flavoprotein DUOX genes and proteins in human papillary and follicular thyroid carcinomas. Thyroid 2001;11:1017-1023.

21. Naiki-Ito A, Asamoto M, Hokaiwado N, et al. Gpx2 is an overexpressed gene in rat breast cancers induced by three different chemical carcinogens. Cancer Res 2007;67: 11353-11358.

22. Florian S, Wingler K, Schmehl K, et al. Cellular and subcellular localization of gastrointestinal glutathione peroxidase in normal and malignant human intestinal tissue. Free Radic Res 2001;35:655-663.

23. Murillo $H$, Huang $H$, Schmidt LJ, Smith DI, Tindall DJ. Role of PI3K signaling in survival and progression of LNCaP prostate cancer cells to the androgen refractory state. Endocrinology 2001;142:4795-4805.

24. Feldman BJ, Feldman D. The development of androgenindependent prostate cancer. Nat Rev Cancer 2001;1: 34-45.

25. Allen GD. MODFIT: A pharmacokinetics computer program. Biopharm Drug Dispos 1990;11:477-498.

26. Yu YP, Yu G, Tseng G, et al. Glutathione peroxidase 3, deleted or methylated in prostate cancer, suppresses prostate cancer growth and metastasis. Cancer Res 2007;67:80438050 .

27. Utomo $A$, Jiang $X$, Furuta $S$, et al. Identification of a novel putative non-selenocysteine containing phospholipid hydroperoxide glutathione peroxidase (NPGPx) essential for alleviating oxidative stress generated from polyunsaturated fatty acids in breast cancer cells. J Biol Chem 2004;279:4352243529.

28. van der Velden LA, Schaafsma HE, Manni JJ, Ruiter DJ, Ramaekers FC, Kuijpers W. Cytokeratin and vimentin expression in normal epithelium and squamous cell carcinomas of the larynx. Eur Arch Otorhinolaryngol 1997;254: 376-383.

29. Redondo S, Ruiz E, Gordillo-Moscoso A, et al. Overproduction of cyclo-oxygenase-2 (COX-2) is involved in the resistance to apoptosis in vascular smooth muscle cells from diabetic patients: A link between inflammation and apoptosis. Diabetologia 2011;54:190-199. 
30. Gresner P, Gromadzinska J, Jablonska E, Kaczmarski J, Wasowicz W. Expression of selenoprotein-coding genes SEPP1, SEP15 and hGPX1 in non-small cell lung cancer. Lung Cancer 2009;65:34-40.

31. Meyer HA, Hollenbach B, Stephan C, et al. Reduced serum selenoprotein P concentrations in German prostate cancer patients. Cancer Epidemiol Biomarkers Prev 2009;18:23862390.

32. Culig Z, Hobisch A, Herold M, et al. Interleukin 1 beta mediates the modulatory effects of monocytes on LNCaP human prostate cancer cells. Br J Cancer 1998;78:1004-1011.
33. Khalili M, Mutton LN, Gurel B, Hicks JL, De Marzo AM, Bieberich CJ. Loss of Nkx3.1 expression in bacterial prostatitis: A potential link between inflammation and neoplasia. Am J Pathol 2010;176:2259-2268.

34. Martin K, Viera K, Petr C, Marie N, Eva T. Simultaneous analysis of cytokines and co-stimulatory molecules concentrations by ELISA technique and of probabilities of measurable concentrations of interleukins IL-2, IL-4, IL-5, IL-6, CXCL8 (IL-8), IL-10, IL-13 occurring in plasma of healthy blood donors. Mediators Inflamm 2006;2006: 65237. 